\title{
Peculiarities of galvanomagnetic effects in nonhomogeneous magnetic field
}

\author{
V.N.Samofalov, A.S.Asieiev, A.G.Ravlik \\ National Technical University "Kharkiv Polytechnic Institute", \\ 2 Kirpichova Str., 61002 Kharkiv, Ukraine
}

Received December 27, 2017

\begin{abstract}
Effect of high-gradient nonhomogeneous magnetic fields on galvanomagnetic properties of condensed bismuth films was studied. Strong high-gradient magnetic fields were created using a system of two $\mathrm{Nd}-\mathrm{Fe}-\mathrm{B}$ permanent magnets. It was established that in $\mathrm{Bi}$ films, a potential difference occurred through magnetic field gradient in addition to Hall emf. In contrast to Hall odd effect, the sign of the "gradient" emf is independent on current and field directions. The revealed phenomenon is defined as Hall gradient effect. It has been experimentally established that the gradient electrical field $E_{G}$ occurs also without electrical current in the conductor. The gradient voltage value attains about $\Delta U_{0} \approx 20 \mu \mathrm{V}$. By the sign of $\Delta U_{0}$, it is possible to determine the predominant carrier type without current in the conductor.
\end{abstract}

Keywords: gradient effect, constant magnet, field fields, bismuth film, galvanomagnetic properties.

\footnotetext{
Изучено влияние неоднородных магнитных полей с большим градиентом на гальваномагнитные свойства конденсированных плёнок висмута. Сильные высоко-градиентные магнитные поля создавали с помощью системы из 2-х постоянных магнитов из $\mathrm{Nd}-\mathrm{Fe}-\mathrm{B}$. Установлено, что в плёнках висмута, кроме ЭДС Холла, возникает также разность потенциалов, обусловленная градиентом магнитного поля. В отличие от нечётного әффекта Холла знак "градиентной" ЭДС не зависит от направления тока и поля. Обнаруженное явление можно определить как градиентный әффект Холла. Также экспериментально установлено, что градиентное электрическое поле $E_{G}$ возникает и при отсутствии тока в проводнике. Величина градиентной разности потенциалов достигала около $\Delta U_{0} \approx 20$ мкВ. По знаку $\Delta U_{0}$ можно определить преобладающий тип носителей без пропускания тока через проводник.
}

Особливості гальваномагнітних ефектів у неоднорідному магнітному полі. В.М.Салофалов, А.С.Асєєв, А.Г.Равлік.

Досліджено вплив неоднорідних магнітних полів із великим градієнтом на гальвано-магнітні властивості конденсованих плівок вісмуту. Сильні високоградієнтні магнітні поля створювали за допомогою системи із двох постійних магнітів з $\mathrm{Nd}-\mathrm{Fe}-\mathrm{B}$. Встановлено, що у плівках вісмуту, окрім ЕРС Холла, виникає також різниця потенціалів, що обумовлена градієнтом магнітного поля. На відміну від непарного ефекту Холла знак "градієнтної" EPC не залежить від напряму струму і поля. Виявлене явище можна визначити як градієнтний ефект Холла. Також експериментально встановлено, що градієнтне електричне поле $E_{G}$ виникає навіть за відсутності струму у провіднику. Величина градієнтної різниці потенціалів сягала близько $\Delta U_{0} \approx 20$ мкВ. За знаком $\Delta U_{0}$ можна визначити переважний тип носіїв заряду без пропускання струму через провідник. 


\section{Introduction}

It is known $[1,2]$ that Hall effect consists in appearance of transversal voltage in a conductor with direct current when it is placed into homogeneous magnetic field; i.e. under crossed fields, the electromotive force (emf) occurs. Appearance of the voltage is caused by Lorentz force shifting charges to one of faces of a parallelepiped shape conductor. Motion of charges in magnetic field $H$ in presence of electrical field $E$ can be represented as a sum of drift motion of Larmor circle itself with velocity $V_{D}=E / H$ and motion of an electron by its orbit [3]. Vector $\mathbf{V}_{\mathbf{D}}$ is directed along the normal to the plane formed by $\mathbf{E}$ and $\mathbf{H}$ vectors. Also, it is known that in magnetic field, an electron moving by Larmor orbit has a large magnetic moment. In high gradient magnetic field, the force of interaction of the field with the magnetic moment may be comparable with Lorentz force. The direction of the force may be different. Presence of such a large force is able to influence on the character of galvanomagnetic phenomena. The aim of the work is studying the Hall effect and other galvanomagnetic phenomena in high gradient magnetic field.

\section{Experimental}

2.1 Preparation of film specimens and magneto-electrical measurements

Bismuth films were prepared by electronbeam evaporation of a bulk perform and condensation onto a glassceramic substrate at a fixed temperature. Film thickness was from 1 to $2 \mu \mathrm{m}$. As contacts, prior condensed copper plates with thickness near $1.5 \mu \mathrm{m}$ were used. Specimens have a shape of a strip with lateral branches; stabilized current passes through the strip, and transversal voltage was measured at the lateral contacts. A schematic circuit of the facility for measurements of Hall emf is shown in Fig. 1. The current through a specimen was $I=1$ ma that corresponded to $j=1 \mathrm{~A} / \mathrm{mm}^{2}$ current density.

\section{field \\ 2.2 Sources of nonhomogeneous magnetic}

Magnetic fields with high strength and large gradient were created using a system of two $\mathrm{Nd}-\mathrm{Fe}-\mathrm{B}$ magnets connected by a magnetic core, Fig. 2a. Specific features of stray magnetic fields generated by the system were described in details in [4-7]. In Fig. 2b and Fig. 3, plots of calculated

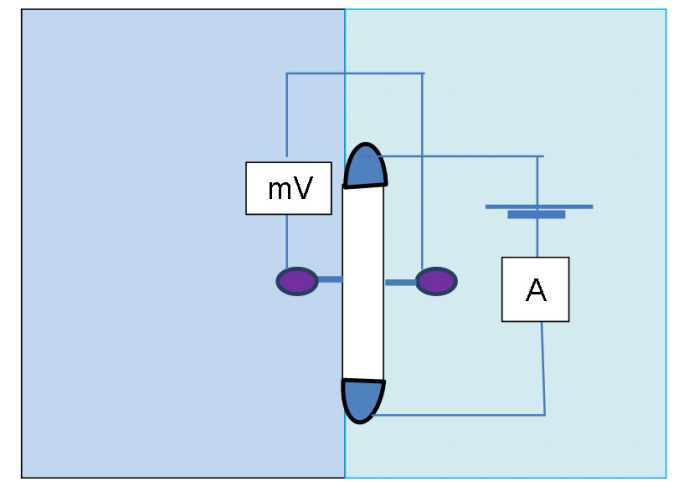

Fig. 1. Schematic circuit for measurement of Hall emf.

$H_{x}(x, z)$ and $H_{z}(x, z)$ components of the stray fields are shown. Validity of high values of $H_{x} \approx 2 \cdot 10^{4}$ Oe has been substantiated and verified experimentally $[4,7]$. The component $H_{y}$ in the points $T(x, 0,0)$ is close to zero because of symmetry. From dependences of Fig. 3 it follows that the largest stray fields are attained at the joint of magnets $(x=0)$ and at their edges $(x= \pm a)$. In these singular points, the gradients for field horizontal $\left(\partial H_{z} / \partial x\right)$ and vertical $\left(\partial H_{x} / \partial x\right)$ components are also the largest: $10^{6}-10^{4} \mathrm{Oe} / \mathrm{cm}$. Such fields can be created only using superconducting magnets at helium temperatures. The noticed features of magnet systems based on rare-earth elements are related with extremely high fields of anisotropy $H_{k}>10^{5}$ Oe. With this anisotropy, magnetization in magnets is practically frozen $[6,8]$.

\section{Results and discussion}

As it was noticed earlier, expected Hall effect features in nonhomogeneous magnetic field may appear due to interaction of gradient field with magnetic moments of current carriers. Analytical description of electron movement in nonhomogeneous magnetic field is a complex problem. Experience shows [3], that the problem is substantially simplified, if complex circular movement of electrons is substituted by drift of Larmor circle itself. So, magnetic moment of a free electron with velocity projection $V_{\perp}$ on the field direction is $M=\mu V_{\perp}^{2} / 2 H$. Existence of magnetic moment for current carriers in nonhomogeneous magnetic field results in occurrence of gradient force $\mathbf{F}_{\mathbf{G}}=\operatorname{grad}(-\mathbf{M} \cdot \mathbf{H})$. If the magnetic moment of an electron is thought constant, the expression for the force is $\mathbf{F}_{\mathbf{G}}=(\mathbf{M} \cdot \nabla) \mathbf{H}$. This force is directed to the area of the lowest absolute field inde- 

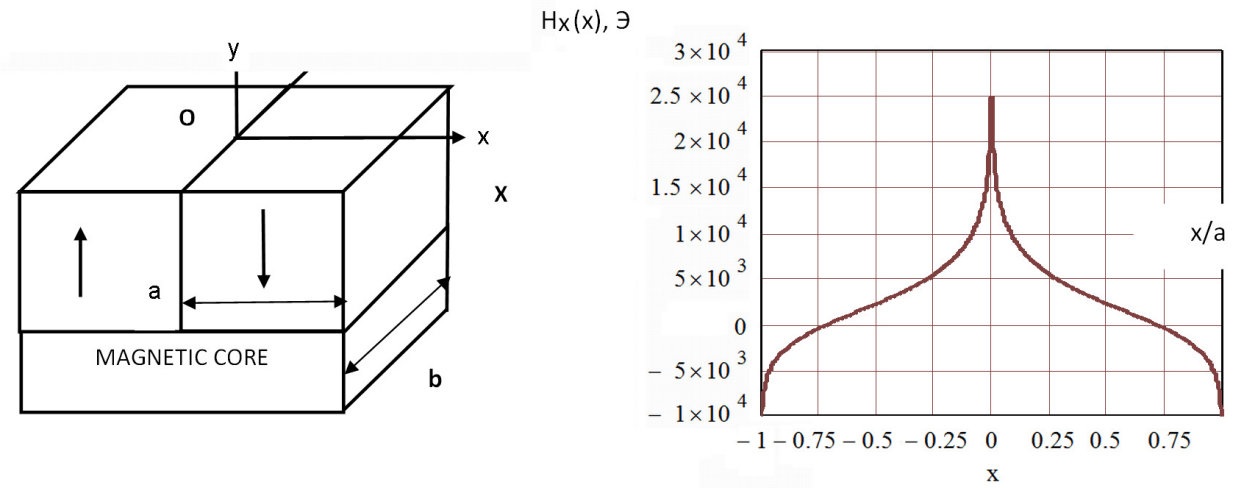

Fig. 2. a) System of two magnets with a magnetic core. b) Plot of scattering field horizontal component $H_{x}$ over surface of the system show Fig. 2a. For calculations, $M_{S}=1000$ Gs was taken.

pendently on the charge direction of movement and sign. As a result of action of the force, charges are accumulated in the areas of the conductor where the field is minimal. The gradient force creates electrical field with strength $\mathbf{E}_{\mathbf{G}}=-\mathbf{F}_{\mathbf{G}} / e$, which we call gradient field. Almost all the "free electrons" participating in thermal movement are in the field of action of this force. Depending on orientation of magnetic field and current through the sample, the gradient field $\mathbf{E}_{\mathbf{G}}$ may coincide with Hall field $\mathbf{E}_{\mathbf{H}}$, or these fields may have different directions. Existence of the gradient field $\mathbf{E}_{\mathbf{G}}$ in the conductor with current in nonhomogeneous magnetic field results in occurring the voltage $\delta U_{G}$ between conductor points being in magnetic field areas with different strength. From abovementioned it follows that the effect of $\delta U_{G}$ variation would be even, i.e. it would not depend on current and magnetic field directions.

In order to verify these conclusions we use a system of two magnets shown in Fig. 2a. Measurements were carried out in magnets' surface points with coordinates $T 1(0,0,0)$, $T 2( \pm a, 0,0)$ and $T 3( \pm a / 2,0,0)$ where stray field components and their gradients had different values. The choice of these points is caused by the fact that only one of the components $H_{x}$ (or $H_{z}$ ) in these points is high but another is close to zero. In the beginning, measurements were carried out in points $T 2(+-a, 0,0)$ according to the scheme shown in Fig. 4a.

The plane of a film sample in the shape of a rectangular strip of $1 \times 12 \mathrm{~mm}$ size and $2 \mu \mathrm{m}$ thickness was parallel to XOY plane and placed at the edge of the magnet, Fig. 4a. The long side of the strip along which the current flowed was parallel to $O Y$ axis. Voltage contacts were placed in the middle

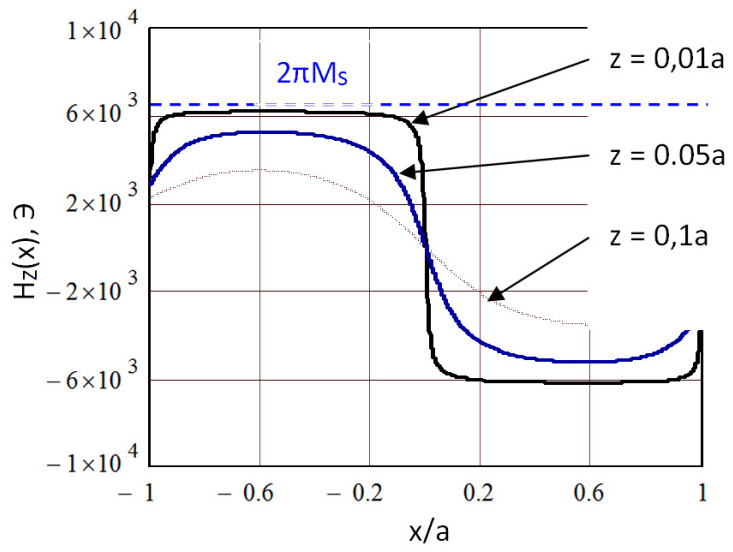

Fig. 3. Plots of scattering field vertical component $H_{Z}(x)$ with different distances $(z)$ from $X O Y$ plane. For calculations, $M_{S}=$ 1000 Gs was taken.

of the strip, Fig. 1, Fig. 4a,b. With such geometry, the stray field component $H_{x}$ and field gradient tensor component $\partial H_{x} / \partial x$ have got high values. Because of sample symmetry: $H_{y} \approx 0$.

Three types of differently directed electrical fields act on current carriers in the conductor: the field from the current source (along $O Y$ ); Hall field $E_{H}$ (parallel to $O Z$ ); and gradient field $E_{G}$. Peculiarities of $E_{G}$ field are not considered here in detail. Hall voltage $\delta U_{H}$ occurs between upper and bottom film surfaces. However, because of absence of necessary contacts at the film sample, this voltage was not measured. Also, it was established, that the sign of potential at the external (to the magnet) contact (Fig. 4a) indicated the predominant type of carriers in the conductor.

Measurements by the scheme Fig. 4a have shown that under current through the sample, voltage $E_{G} \approx 30-35 \mu \mathrm{V}$ appears be- 


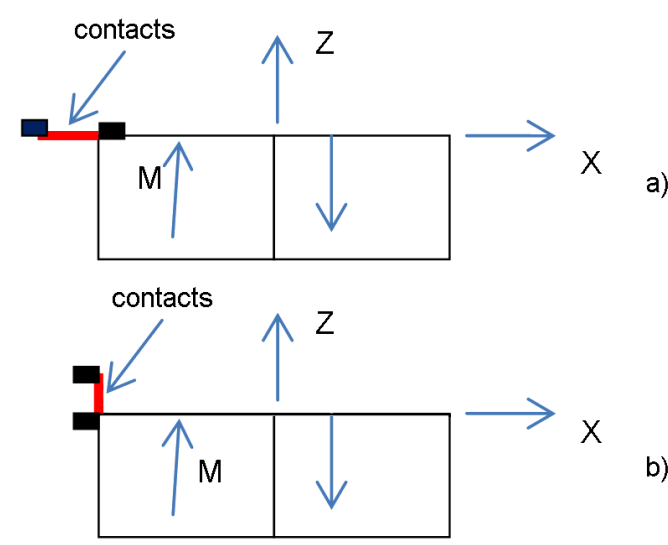

Fig. 4. Scheme of sample location over the magnet system for measurements of Hall emf.

tween the contacts. With changing the direction of current (or field) by opposite, the voltage changes a little, and $\delta U_{G}$ sign is the same. As it is seen, in nonhomogeneous field, occurrence of emf in the conductor is the even effect. We consider that the revealed even effect of emf occurrence in nonhomogeneous field is a type of Hall effect, so, it can be defined as gradient Hall effect.

In the case where the sample is positioned as shown in Fig. 4b, both Hall field and the gradient field are parallel to $O Z$ axis. In this case, the gradient field $E_{G z}$ is created by $\partial H_{x} / \partial z$ component of the field gradient tensor. Then, these fields are parallel for one current direction, while these are anti-parallel for another direction. Consequently, the measured emf, $\delta U$, would be equal to the sum of Hall emf, $\pm \delta U_{H}$, and the emf of the gradient field, $\delta U_{G}$; i.e. $\delta U=$ $\delta U_{G} \pm \delta U_{H}$. Our measurements have given the following emf values: $\delta U_{1} \approx+120 \mu \mathrm{V}$, $\delta U_{2} \approx-60 \mu \mathrm{V}$.

Also, emf were measured in the point $T(a / 2,0,0)$ where the vertical component $H_{z}$ of stray field has high values (Fig. 2). In this point, the field component $H_{x} \approx 0$, and gradient tensor components: $\partial H_{x} / \partial x \approx 0$ and $\partial H_{z} / \partial z \approx 0$, i.e. the gradient field is absent, $E_{G}=0$. The plane of the film sample was parallel to the magnet $X O Y$ plane. Measurements of voltage with anti-parallel directions of current have given the following emf values: $\Delta U_{H 1}=50 \mu \mathrm{V}, \Delta U_{H 2}=-55 \mu \mathrm{V}$. These are purely Hall's emf values.

It should be noted, that obtained experimental results require more detailed calculations taking into account electrical fields of different nature. In the present work, on purpose of qualitative understanding of the revealed features of Hall effect, we confined ourselves by the classical conception on gas of "free electrons" in the conduction band. It follows from abovementioned that when the conductor is placed into magnetic field, the gas of free electrons gets magnetic moment directed towards the field. Such "diamagnetism" is related with the fact that each electron has some velocity which may attain $10^{8} \mathrm{~cm} / \mathrm{s}$ at Fermi level. Under magnetic field, $H$, electrons begin precession around the axis parallel to the external field direction. Magnetic moment of each electron is determined by velocity component, $V_{\perp}$, normal to field $H$ direction, i.e. $M=\mu V_{\perp}^{2} / 2 H$, and it may attain $10^{-15} \mathrm{erg} / \mathrm{Oe}$. Because electron velocity in the conduction band $V \perp \neq 0$, practically all the electrons possess some magnetic moment. This magnetic moment is directed towards the field $H$ for all the electrons. Energy of an electron moving by Larmor orbit is positive: $W=-(-M, H)$ $>0$, so, in nonhomogeneous field $H$, electrons would shift to the minimum field area. The shift would take place until occurred electrical fields compensate the gradient forces. The pattern of charge distribution would be complex. Possibly, besides charges on external surfaces of the sample, in nonhomogeneous field also volume electrical charges appear in points where div $E$ $\neq 0$.

From above arguments it follows that in a conductor being in nonhomogeneous magnetic field, a voltage would occur between points which are in field areas of different strength even without current $i$ through the sample. Our measurements has established that this voltage exists really even at $i=0$. Multiple measurements carried out on various film samples of $1 \mathrm{~mm}$ width in nonhomogeneous fields with gradient $10^{4}-10^{6} \mathrm{Oe} / \mathrm{cm}$ showed voltages $\Delta U_{0} \approx 20 \mu \mathrm{V}$. Measurement error was about $2-5 \mu \mathrm{V}$. As it is seen, electrical field in a conductor can be created using nonhomogeneous magnetic field, i.e. a conductor in magnetic field may transform thermal energy into electrical. Also, a principal possibility exists for application of this property in refrigeration units.

\section{Conclusions}

The revealed phenomenon is not Hall effect and requires more detailed investigation for its classification. Because in the absence of external electrical field $(E=0)$, velocity of electrons is determined by tem- 
perature of the conductor, one should expect increasing $\Delta U_{0}$ under heating. Also, notice that using magnet systems with high gradient field, one can determine the type of carriers by the sign of $\Delta U_{0}$ in the conductor without current. In order to find out the possibility for determination of carrier concentration, $n$, by $\Delta U_{0}$, simulating calculations are necessary.

\section{References}

1. E.V.Kuchis, Galvanomagnetic Effects and Methods of Investigation, Radio and Communication, Moscow (1990) [in Russian].
2. V.L.Bonch-Bruyevich, Physics of Semiconductors, Nauka, Moscow (1990) [in Russian].

3. L.A.Artsimovich, R.Z.Sagdeyev, Physics of Plasma for Physicists, Atomizdat, Moscow (1979) [in Russian].

4. V.N.Samofalov, A.G.Ravlik, D.P.Belozorov et al., J.Magn. Magn. Mater., 281, 326 (2004).

5. V.N.Samofalov, D.P.Belozorov, A.G.Ravlik, FMM, 102, 527 (2006).

6. V.N.Samofalov, D.P.Belozorov, A.G.Ravlik, $U F N$, 56, 3 (2013).

7. S.I.Tarapov, V.N.Samofalov, A.G.Ravlik et al., Intern. J. Infrared Millimeter Waves, 24, 1082 (2003).

8. V.N.Samofalov, D.P,Belozorov, A.G.Ravlik et al., Functional Materials, 24, 1 (2017). 